\title{
Flaring Intensity Monitoring: Applications at Different Levels of Nigerian Petroleum Upstream Industry
}

\author{
P. N. Ndunagu ${ }^{1 *}$, O. F. Joel ${ }^{1}$, A. A. Oji ${ }^{2}$, E. E. Alaike ${ }^{3}$ \\ ${ }^{1}$ World Bank African Centre of Excellence in Oil Fields Chemical Research, Rivers State, Nigeria. \\ ${ }^{2}$ Department of Chemical Engineering, University of Port Harcourt, Rivers State, Nigeria. \\ ${ }^{3}$ VFuels Oil and Gas Engineering, Houston Texas, USA.
}

ABSTRACT: Flare volume measurement has been the sole yardstick for tracking flare gas reduction progress and provides a single view of monitoring in the context of its use. In this study, an alternative method was introduced to broaden the perspective of flare gas monitoring. Flaring intensity is a simple and effective measure for tracking flare gas reduction. Flaring Intensity index was applied in different levels of flare volume estimation, namely Oilfield, Oil Company, Petroleum Upstream Contract and Country. Nigerian Petroleum Production data were sourced from regulatory reports and satellite data from 2012 to 2015 and 2018 annual reports. The results revealed that Nigeria's flaring intensity is on the decline due to exogenous factors and it illustrates flaring intensity as a comparative and benchmarking tool for gas flare performance at various hydrocarbon production levels. The study also inferred that improved flare gas measurement, transparency in reporting, robust regulation and increased gas handling infrastructure were necessary in order to mitigate flaring in Nigeria to achieve the 2030 Zero Routine Flaring target.

KEYWORDS: Oil field, Nigeria gas flare tracker, department of petroleum resources, associated gas, flare site.

[Received May 26, 2021; Revised Oct. 8, 2021; Accepted Nov. 9, 2021]

Print ISSN: 0189-9546 | Online ISSN: 2437-2110

\section{INTRODUCTION}

In Nigeria's oil-rich region of the Niger Delta, it is important to keep track of emissions from oil production facilities in other to; understand its environmental impact, monitor the progress of flare down programme/policies and identify potential gas utilisation opportunities. Nigeria has the 9th largest gas reserves in the world at about 203.16 Trillion standard cubic feet (Tscf) (DPR, 2020). Though Nigeria's gas utilisation is steadily growing, $11 \%$ of the gases were flared (324 Billion standard cubic feet) in 2018, as shown in Figure 1 , which is primarily Associated Gas (AG), making Nigeria the 7 th highest gas flaring country in the world.

Gas flaring is a method of disposing gaseous hydrocarbons produced in an oil and gas production facility by burning the gases in a flare (flare stack) and releasing them into the atmosphere. This method of combustion is known as the Open Diffusion Flame Process (Banerjee et al., 1985). Associated Gas (AG) which is produced with the oil remains the largest source of gas flare globally. Flaring can generally be classified into routine, safety, and non-routine flaring. Routine flaring occurs during normal oil production operations and is caused by various factors such as inadequate local demand, unavailability of market, unsuitable reservoir geology for gas injection operation, technical and physical constraints, and poor economics of gas monetisation. The
"Zero Routine Flaring by 2030" initiative introduced by the World Bank is a commitment by Governments, Oil Companies, corporate bodies, and Development Institutions to cooperate and eliminate routine flaring before 2030. Safety flaring is used to ensure safe operation of the facility onsite by applying processes such as blow-down and line depressurisation, while Non-routine flaring is flaring other than routine and safety flaring.

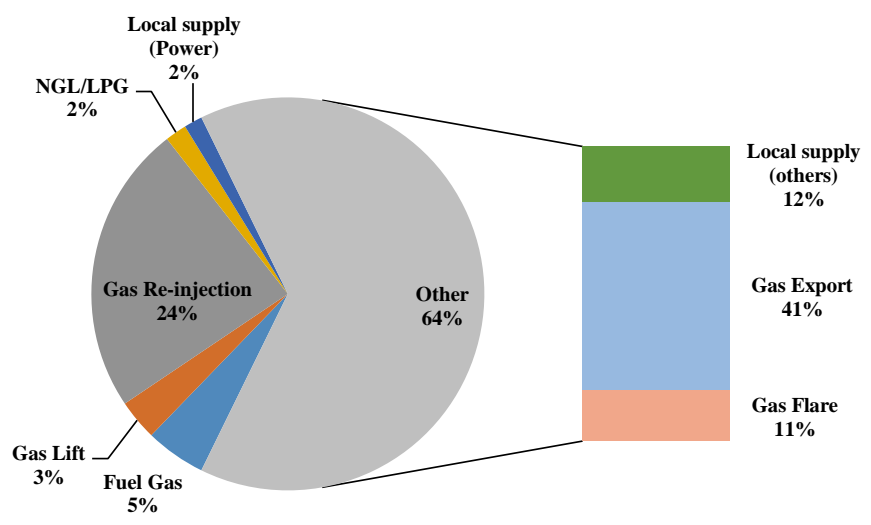

Figure 1: The breakdown of gas utilisation in Nigeria in 2018 Source: (DPR, 2018) and author's illustration. 
Gas flaring is considered a serious health and environmental issue in Nigeria (Osuoha \& Fakutiju, 2017).

Dung, et al, (2008) showed that the flaring of associated gas hinders the growth of some tropical cash crops. Studies also show that gas flaring can reduce the soil quality (Ubani \& Onyejekwe, 2013), rainwater quality (Ogolo, et al., 2018) and affect the integrity of zinc roofs of houses. It has also been reported that routine gas flaring causes noise pollution and perpetual illumination at night (Emam, 2015). Greenhouse gases such as carbon dioxide $\left(\mathrm{CO}_{2}\right)$ and methane $\left(\mathrm{CH}_{4}\right)$ are present in flare gases effluent and are amongst the major causes of global warming. Other studies show that air pollution through the release of gaseous oxides such as sulphur dioxide $\left(\mathrm{SO}_{2}\right)$, Volatile Organic Compounds (VOCs) and soot can cause respiratory health issues. These emissions need to be reduced for natural gas to achieve its energy transition fuel status. Nigeria has shown commitment to reduce gas flaring activities in the petroleum upstream sector as it is a signatory to World Bank's Zero routine gas flaring reduction by 2030 initiative signed in June 2016.

Another International commitment is the 2015 Paris Climate Change Agreement, which shows its commitment to ending routine flaring by taking mitigative measures to combat global warming. An important aspect of mitigating gas flaring is flare gas monitoring. Flare gas monitoring is a challenge in Nigeria, making it difficult to quantify the volume of emission discharged into the atmosphere and its corresponding environmental effects. According to Diaa (2021), many of the flares in the Niger Delta region do not have flare gas meters, leading to uncertainties on reported estimates of the total volume of flared gas. Reported flare volumes are often based on a variety of calculation methods (like using Total Gas Oil Ratio to estimate flare volumes) other than direct measurement of the gas sent to the flare stack (Olin, 2014). The operators report this information to the Nigerian petroleum industry regulator, the Department of Petroleum Resources (DPR), every month.

It has been reported that operators and sometimes regulators (Romsom \& McPhail, 2021; Haugland et al., 2013) may benefit from inadequate reporting of flare gas volumes through financial, commercial and reputational favours, reemphasising the need for adequate monitoring. However, Mylvaganam (1989) recommended that ultrasonic meters are the most suitable type of meters for flare volume measurement and have been proposed for use in Nigeria. Satellite technology is also used to detect and monitor gas flaring activities globally, as shown in Figure 2. With the Visible Infrared Imaging Radiometer (VIIRS), a multispectral imaging technology, on-board satellites like the Suomi NPP satellite, specific infrared or thermal radiation such as gas flares can be detected and estimated in real-time. This remote sensing technology can estimate flare gas volumes with $\pm 9.5 \%$ accuracy (Elvidge, et al., 2015) and can assist in areas

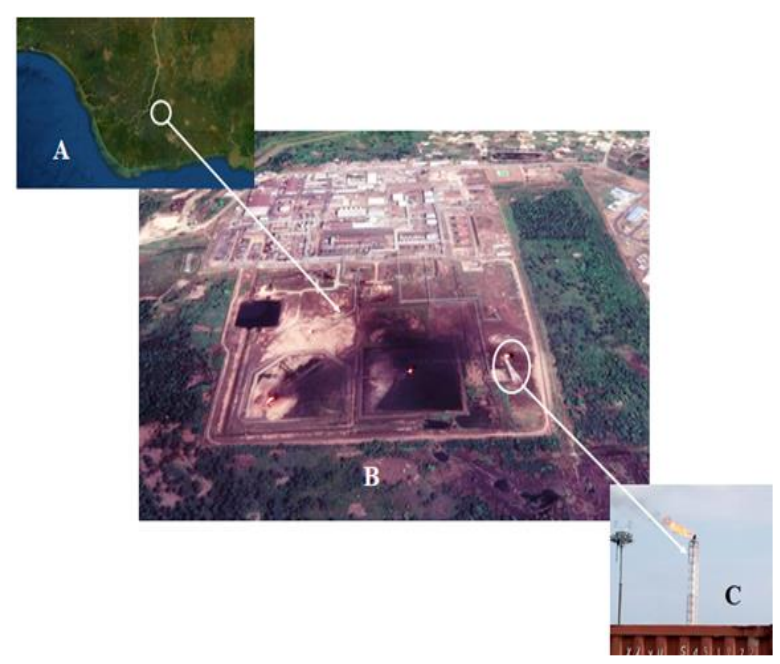

Figure 2: Satellite view of Niger Delta region, Obirikom Oil Field (A and B) and Ground view (C) of Flare stack. Source: (Google, 2019) and (Ndunagu, 2021).

that do not have technical resources or political will to monitor flare gas emission. Studies carried out by (Hodgson, 2018) estimated flare volumes in Nigeria using data of radiant heat from the VIIRS Night Fire (VNF) on-board the Suomi NPP satellite from 2012 to 2016.

The online open-source satellite flare gas monitoring databases available are the Nigeria Gas Flare Tracker (NGFT), which is an initiative of the National Oil Spill Detection and Response Agency (NOSDRA, 2014) and SkyTruth (SkyTruth, 2020). Nigeria is considered the most advanced nation for its measurement of flare data from the NGFT via the VIIRS satellite for oil and gas upstream operations and has set penalties as an effective deterrent to stop routine gas flaring. According to the new regulation approved in 2018, the penalties were raised from $\$ 10$ per Mscf (1000 scf) to $\$ 0.5$ per Mscf for companies producing less than $10,000 \mathrm{bbl} / \mathrm{d}$ of crude oil and $\$ 2.0$ per Mscf for companies producing more than $10,000 \mathrm{bbl} / \mathrm{d}$ of crude oil.

\section{FLARING INTENSITY MONITORING}

Flare volume estimation or measurement has long been the sole means for monitoring flare reduction progress and provides a single view of progress or regress in the context of its use. Sitton, (2020) revealed that this is an incomplete and oversimplified approach as it does not consider other factors such as changes in oil production, the volume of gas being flared relative to the quantity of oil produced, flaring practices and impact from other participants (countries, companies and oilfields) during oil production. Sitton (2020) argued that, since the primary cause for increased flaring activities is increased oil production, a standard needs to be established to relate the volume of gas flared to the quantity of oil produced, referred to as Flaring Intensity (FI). Flaring intensity can be defined as the volume of gas being flared in meter cube $\left(\mathrm{m}^{3}\right)$ or thousand cubic feet (Mcf) per the volume of oil produced in barrels (bbl.) represented as $\mathrm{m}^{3} / \mathrm{bbl}$ or $\mathrm{Mcf} / \mathrm{bbl}$. This index 
is strictly used for measuring the utilisation of gas produced from an oil reservoir for economic and social benefits. The World Bank employs it through the Global Gas Flaring Reduction Partnership (GGFRP) (World Bank, 2019) as a tool to monitor flare gas reduction in different countries and by the Texas Railroad Commission (Sitton, 2020). It is also used as a benchmarking measure for flaring and venting activities in countries like the United Kingdom (OGA, 2020), former Soviet bloc countries (Haugland et al., 2013) and major international oil companies such as Chevron (Chevron, 2020), Shell (Shell, 2015), Eni (United Nations, 2012) and ExxonMobil (ExxonMobil, 2020).

According to (World Bank, 2019), the top three flaring intensity countries are Syria $\left(85.08 \mathrm{~m}^{3} / \mathrm{bbl}\right)$ and Cameroon $\left(41.47 \mathrm{~m}^{3} / \mathrm{bbl}\right)$ and Venezuela $\left(29.81 \mathrm{~m}^{3} / \mathrm{bbl}\right)$. Norway $(0.25$ $\left.\mathrm{m}^{3} / \mathrm{bbl}\right)$, Saudi Arabia $\left(0.59 \mathrm{~m}^{3} / \mathrm{bbl}\right)$ and Canada $\left(0.65 \mathrm{~m}^{3} / \mathrm{bbl}\right)$ have the lowest flaring intensities in the world. Studies have further shown that when infrastructure, regulatory policies and markets are in place for gas utilisation, the flaring intensity index generally tends to be low and vice versa hence giving an insight into the gas utilisation status of oilproducing countries. Saudi Arabia has low flaring intensity because its oil production uses large-scale water flooding, which produces little associated gas and large investment in gas processing infrastructure (Sitton, 2020). Canada's oil is mostly gotten from oil sands that have very little associated gas and Norway due to stringent flaring regulations, government legislation, and enforcement.

The Flaring Intensity index is influenced by total gas-oil ratio, gas utilisation rate, and waste disposal method (Capterio, 2020). The gas-oil ratio (GOR) is a dimensionless unit (i.e. volume per volume) that describes the ratio of the volume of gas that comes out of solution to the volume of oil at standard conditions. It is an important parameter used to characterise oil (Guo, 2019) and can be obtained from oil and gas sales data (El-Banbi et al., 2018). Gas utilisation depicts all other uses of the gas except venting or flaring, which are the two main types of disposal methods. Gas lift and/or gas reinjection are common in order to sustain oil production (Odjugo, et al., 2020). The mathematical expression is Flaring intensity formula (Capterio, 2020) illustrated:

$$
\text { Produced Gas }=\text { Oil Produced } * \text { GOR }
$$

$$
\begin{aligned}
& \text { Flaring volume }=\text { Oil Produced } * \text { GOR } *(1- \\
& \text { Gas Utilization }) * \frac{\text { Flare }}{\text { Flare }+ \text { Vent }} \\
& F I=G O R *(1-\text { Gas Utilization }) * \frac{\text { Flare }}{\text { Flare }+ \text { Vent }}
\end{aligned}
$$

When venting is not accounted for, the equation reduces to

Flaring Intensity $=$ GOR $*(1-$ Gas Utilization $)$

The Flaring Intensity index tends to be an objective performance standard to assess the flare reduction progress but most flare gas reduction efforts have been analysed and reported from a national or territorial point of view based on flare volume alone. This approach does not consider oil fields, oil companies and their levels of contribution to flare emission. In this study, the flaring intensity index was adapted for selected oil fields and companies based on their Joint Venture Agreement with the Nigerian Government to understand flaring levels and examine how various companies perform among their peers using their annual oil and gas production information for 2018.

\section{METHODOLOGY \\ A. Population and Sampling Technique}

Flare sites in the Niger Delta region operated by Shell Petroleum Development Company (SPDC) were chosen for this study. They were sampled purposively based on the visibility of flare sites from satellite aerial view (geo-location) and the availability of flare volume data.

\section{B. Sources of Data}

The data used for this research were quantitative secondary data from the following sources: Nigeria Gas Flare Tracker (NGFT) for monthly flare volume estimates, Nigerian National Petroleum Corporation (NNPC) Monthly Petroleum Information (MPI) report for monthly oil production data and the 2018 Nigerian Oil and Gas Industry Annual Report (NOGIAR) by the DPR.

Based on the recommendation by (Hodgson, 2018), the NNPC MPI dataset for flare gas estimates could not be used due to some limitations summarised below;

(i.) Numerous missing monthly report figures per oil field.

(ii.) The summation of the monthly flare gas reported does not add up to the annual flare gas report.

(iii.) Monthly gas flare volumes varied by a factor of 10 , 100 and sometimes 1000 leading to serious errors and confusion as to whether the unit of measurement is Mscf or MMscf and sometimes altering the annual reports.

Hence, the NGFT satellite dataset was used for further analysis. Figure 3 shows the dataset and period (March 2012 to August 2015) was considered for the monthly flaring intensity index determination. By combining the satellite images from NGFT and Google Earth, the locations of the flares in the Niger Delta region were determined and used for this study.

\section{Methods of Data Analysis}

The data considered were subjected to quality checks to identify outliers and missing data. Furthermore, graphical representations of Oil Production, Flare Volume and Flaring Intensity index were shown in graphs to illustrate the concept of flaring intensity monitor for the selected fields (monthly basis) and companies (annual basis). Furthermore, the companies under the Nigeria upstream Joint Venture (JV) agreement were analysed using the Flaring Intensity index and Utilisation rate.

\section{RESULTS AND DISCUSSION}

The analyses of flaring intensity monitoring were discussed at four (4) different levels shown in Figure 4 by using petroleum production data to explain its relevance. 


\section{A. Flaring Intensity Monitoring for Oil Fields}

In Nigeria, numerous oil fields produce different crude oil grades (light to medium) with characteristic low sulphur identify fields for possible flare gas commercialisation schemes depending on the reliability and characteristics of the flare volumes.

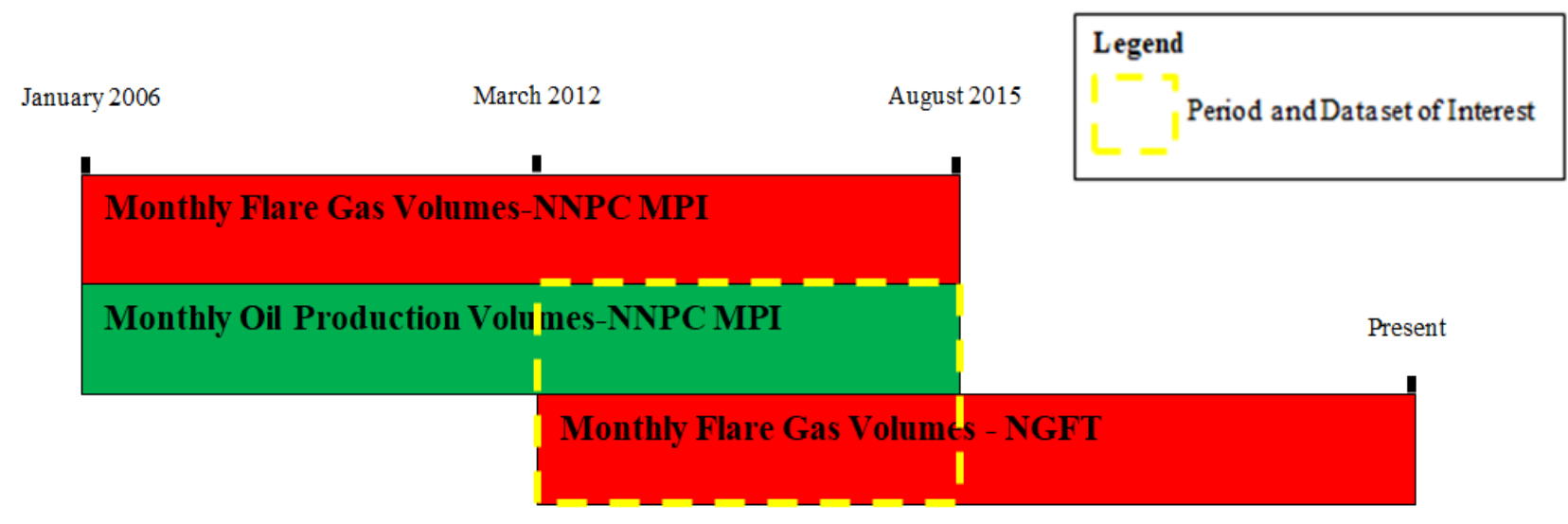

Figure 3: Dataset availability (monthly) timeline for oil fields.

content. Accurate monitoring of flaring activities at the oil fields is fundamental as other levels of monitoring depend on it. The Tunu oil field located at OML 46 (mangrove swamp terrain) and currently operated by SPDC was used to illustrate the application of flaring intensity monitoring.

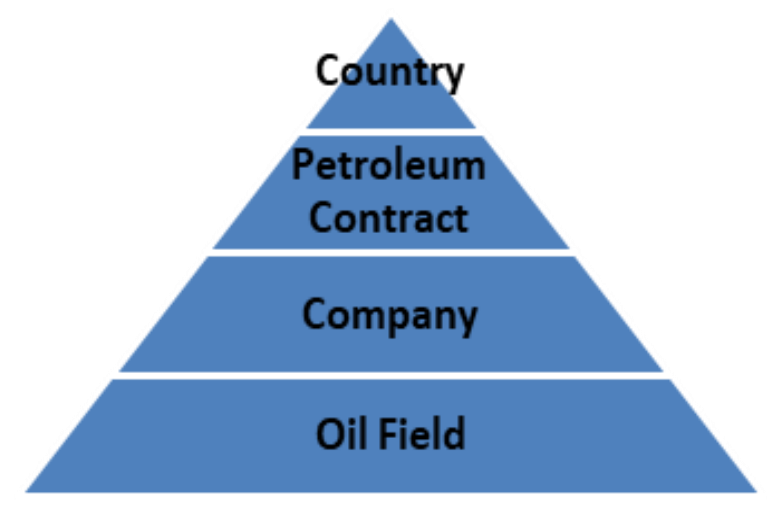

Figure 4: Levels of application of flare gas monitoring.

As shown in Figure 5, the monthly production data illustrates that though the oil production was steady at approximately 125,000 barrels per month, there was a decline in gas flare volumes, which shows significant gas utilisation resulting in a decline of flaring intensity.

\section{B. Flaring Intensity Monitoring for Companies}

Based on the production data from the oil fields, companies can analyse the performance of their assets regarding flare gas reduction. In Figure 6, an annual flaring intensity profile for some SPDC oil fields are shown from 2012 to 2015. It was observed that the oil fields that tend to have high flaring intensity but generally showed a decline suggesting that SPDC was undergoing gas flare reduction projects such as the associated gas-gathering facility in Otumara oil field (Shell, 2018). It was also reported that the flaring intensity of its facilities reduced by $70 \%$ between 2002 and 2015 (Shell, 2015). With this approach, stakeholders can

\section{Flaring Intensity Monitoring among Joint Venture Companies}

In the Nigerian Petroleum Industry, five (5) major contracts permit the exploration and production of petroleum and they include Joint Venture (JV), Production Sharing Contract (PSC), Sole Risk, Service Contract and Marginal field contracts. The Joint Venture agreement is the largest of these contracts with about 60 Oil Mining Licenses (OMLs) (Pitman \& Chinweze, 2018) comprising various International and Local Companies. Analyses were carried out for the major international companies partaking in the JV contract and illustrated in Figure 7. These companies include Shell (SPDC), Total (T E\&P), Exxon Mobil (MPL), Chevron (CNL) and Eni (NAOC).

Based on the NOGIAR for 2018, it can be observed that $\mathrm{T} E \& \mathrm{P}$ has the least flaring Intensity and Natural gas flared percentage of it combined producing oil fields in the Niger Delta. This indicates that investments have been made in planning and developing the associated natural gas resources for end-use like Liquefied Natural Gas (LNG) and the domestic gas market. SPDC is next in terms of performance. It is important to highlight that most IOCs are divesting lowvalue oil fields, improving their flare performance outlook. JV international companies generally perform better than other companies because of their established and expanding gas handling infrastructure such as the Nigeria LNG, West African Gas Pipeline, Numerous gas pipelines for domestic gas supply for power and petrochemical industries (NAPIMS, 2021).

\section{Flaring Intensity Monitoring for Niger Delta Region (Nigeria)}

Flaring intensity has been used mostly for monitoring the flaring performance of various countries to infer the status of gas utilisation, oil production levels and characteristics of the produced hydrocarbon fluid relative to the gas flared. Based on the NOGIAR 2018 report data, the Oil Production, Flare Gas volume, Percentage AG Flared and Flaring Intensity were plotted from 2010 to 2018, as shown in Figures 8 and 9. 


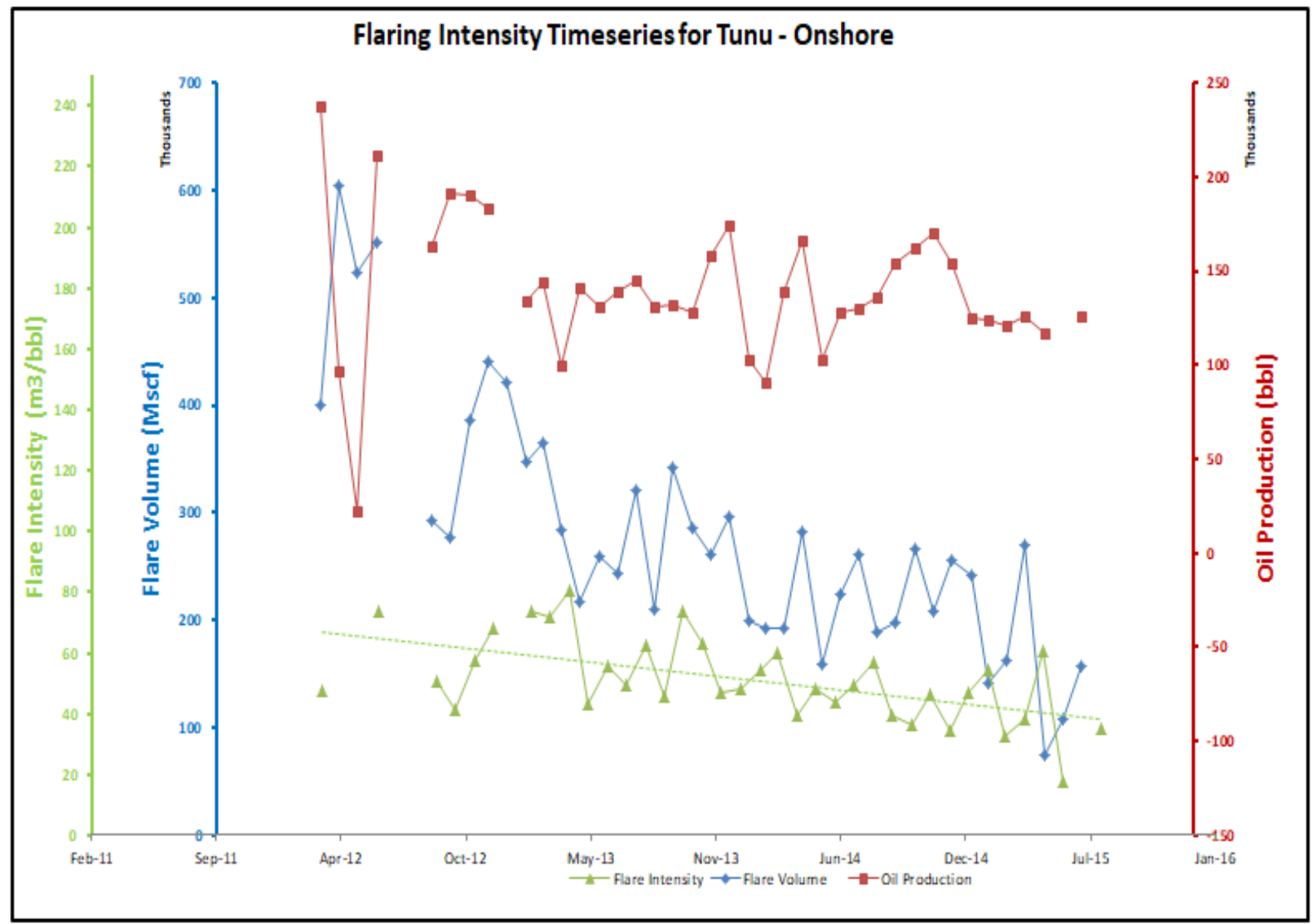

Figure 5: Flaring intensity time series for tunu oil field.

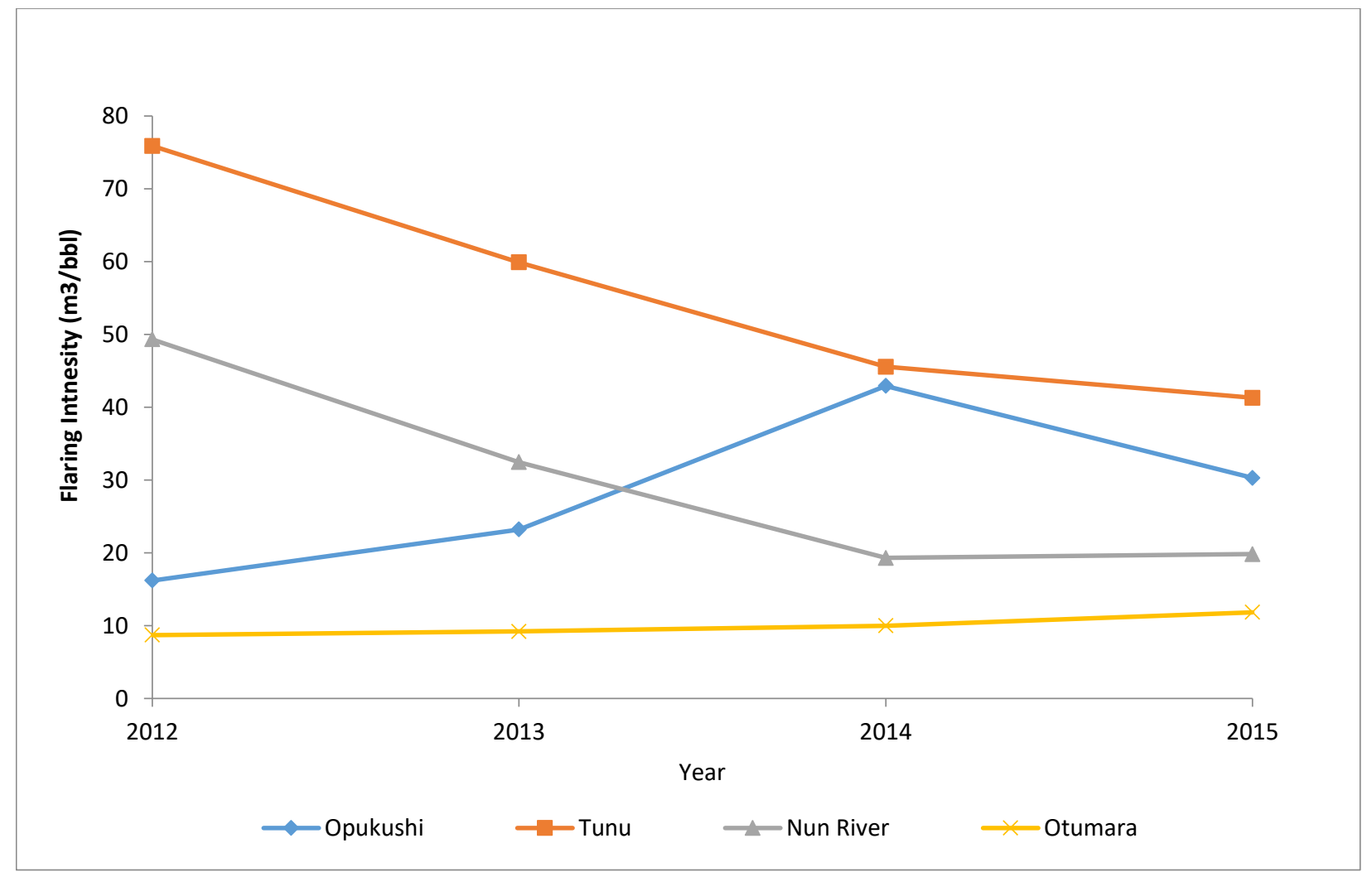

Figure 6: Flaring intensity time series for some SPDC oil fields. 


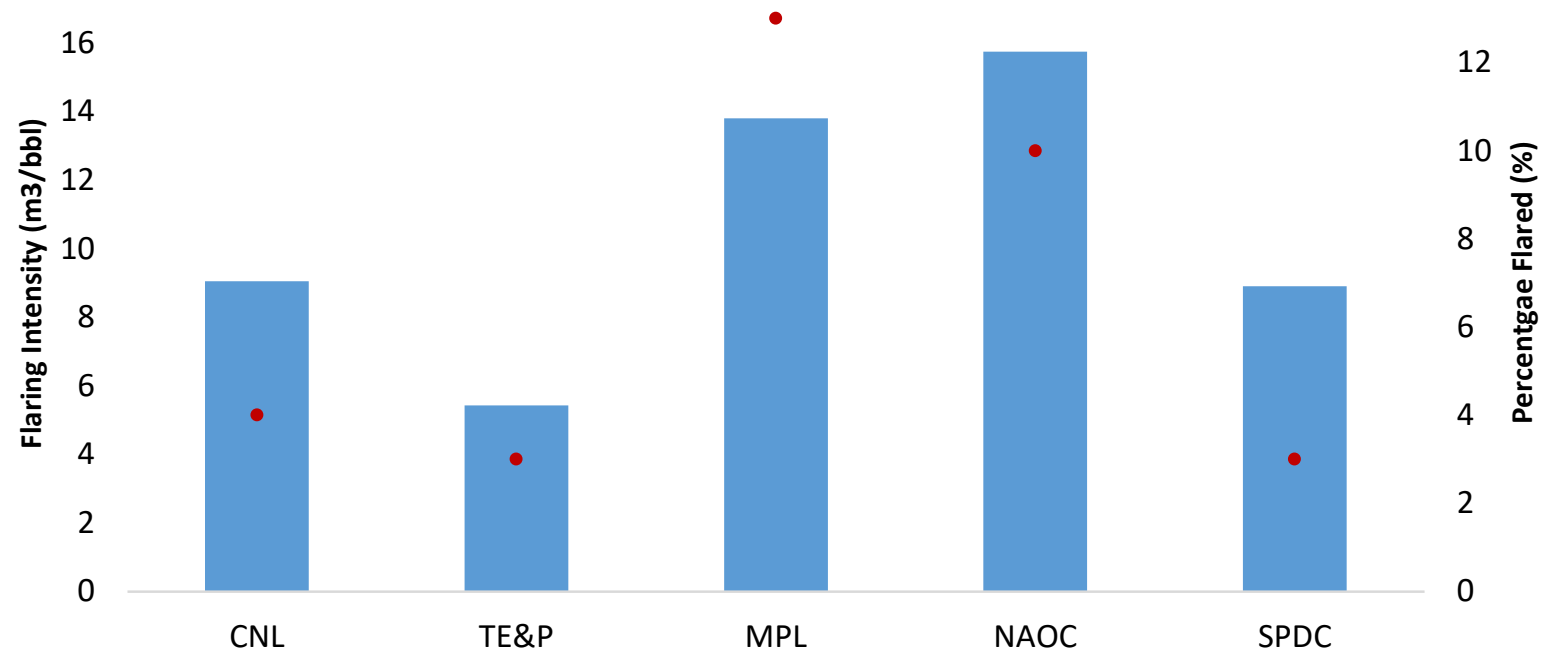

Figure 7: Flaring intensity and percentage flared for JV International companies in 2018.

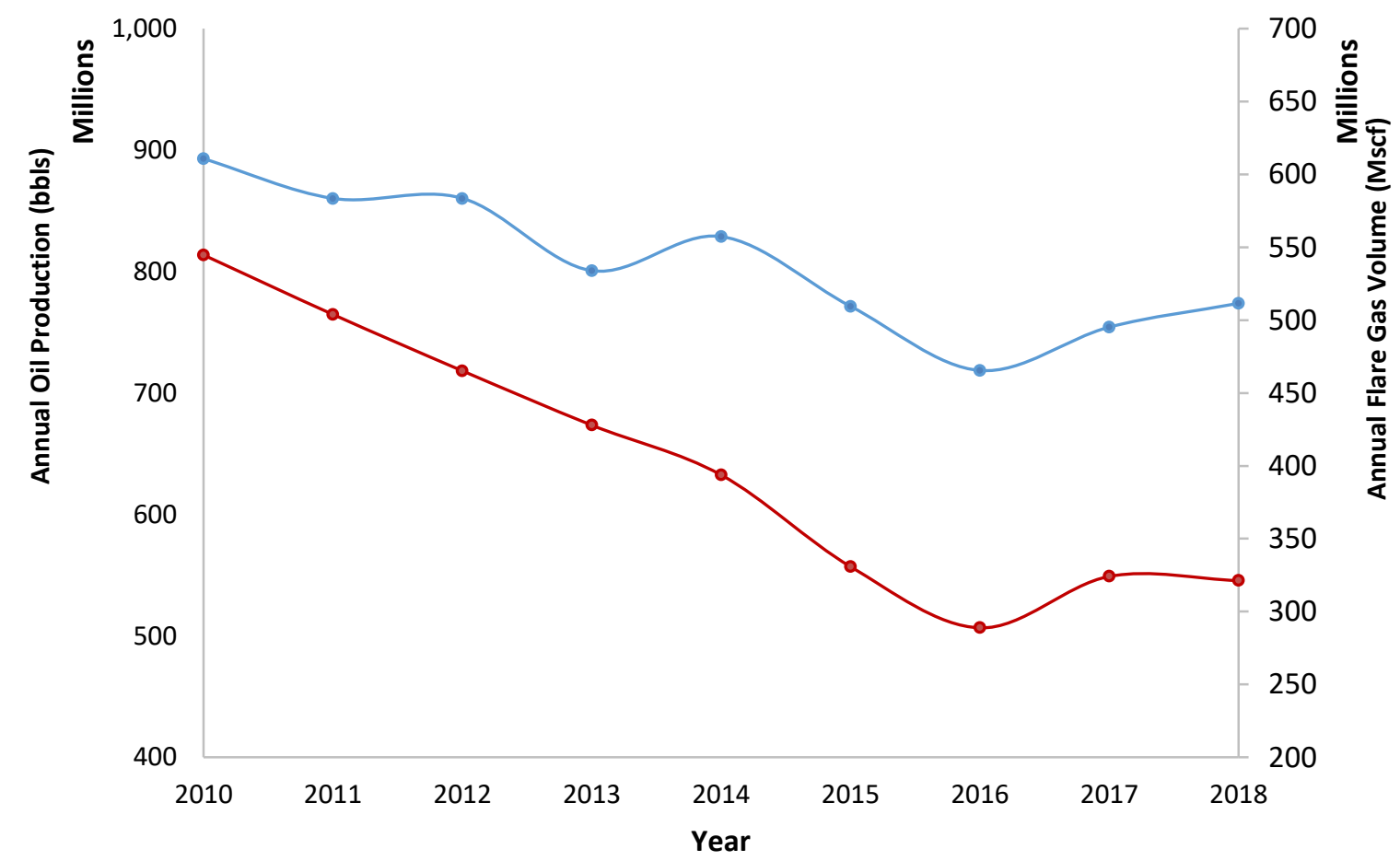

Figure 8: Nigeria oil production and flare gas volume profile (2010 - 2018). 


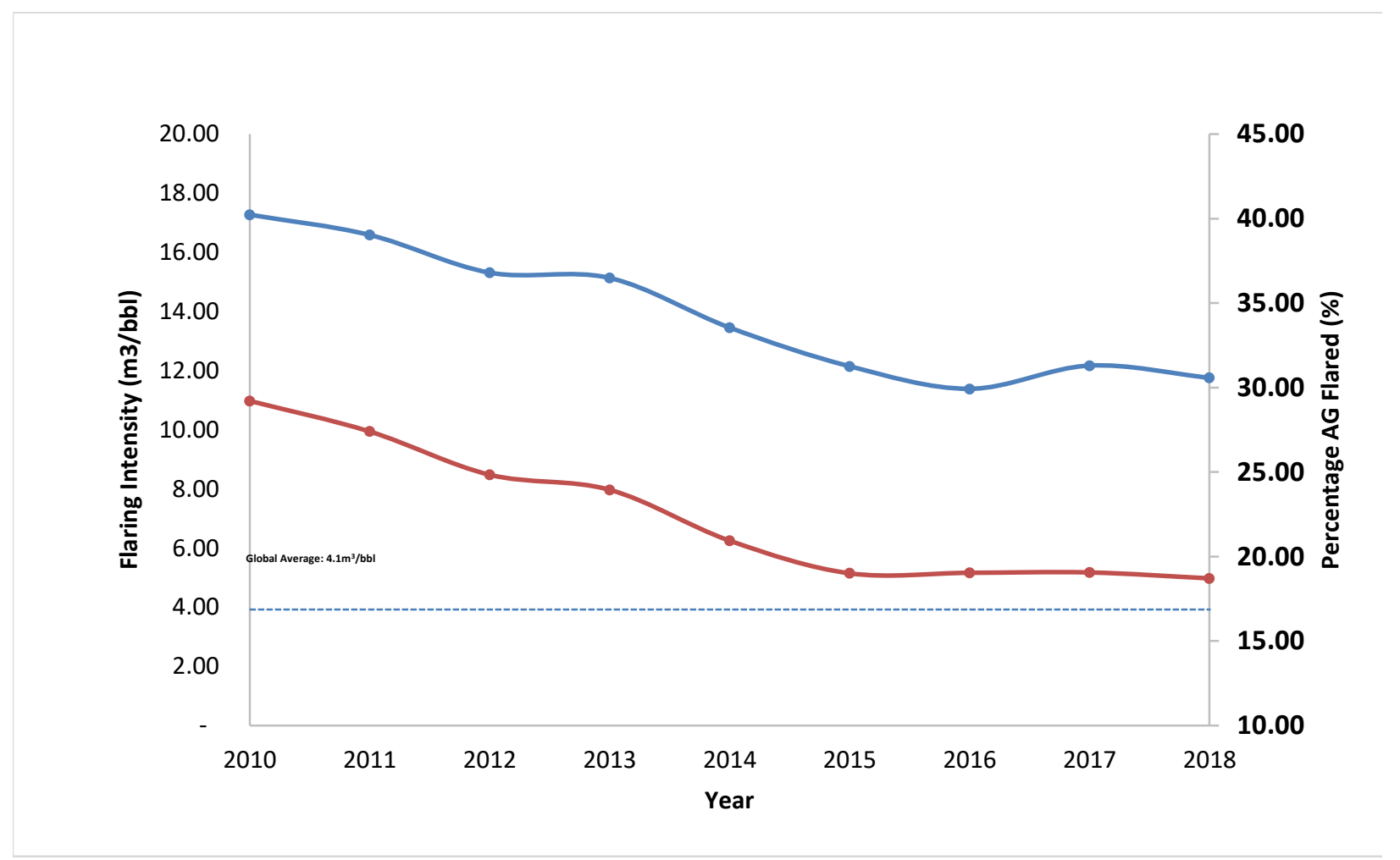

Figure 9: Nigeria flaring intensity and percentage AG flared (2010 - 2018).

There has been a gradual decline in the volume of gas being flared, resulting in a lower flaring intensity. This can be attributed to declining oil production and increased gas utilisation (i.e. the declining percentage of flared associated gas). Oil production cuts have been prevalent in recent years due to controlled oil prices in the international market (2015 - 2021) and attacks in some oil pipelines and oil fields (2012 - 2013) also contributed to the shrinking oil production. Similarly, there has been a gradual and appreciable reduction of AG flaring over the years $(64.48 \%$ in 2001 to $18.71 \%$ in 2018). This reduction in flaring is closely related to the reduction of oil production, as depicted in the graph in Figure 8. According to the World Bank, the global average flaring intensity is $4.1 \mathrm{~m}^{3} / \mathrm{bbl}$ and based on the NOGIAR data, Nigeria's flaring intensity in 2018 was $11.76 \mathrm{~m}^{3} / \mathrm{bbl}$, as illustrated in Figure 9. This indicates that the Nigerian Petroleum Industry needs to employ strategic methods to reduce gas flaring.

The "Diamond Model", as proposed by Romsom \& McPhail (2021), suggests that to end routine gas flaring in low and middle-income countries, a combination of four (4) welldefined steps would need to be taken. These pragmatic steps are shown in Figure 10. According to Romsom \& McPhail (2021), 85\% of the total gases flared are in developing countries while citing the importance of avoiding upstream gas flaring and venting. Limiting and utilising these gases is a major step in achieving energy transition towards light carbon or net-zero carbon future as the effects of climate change unravels. Nigeria is currently an example of the application of the Diamond Model considering the open-source Gas Flare Tracker and new regulatory guidelines to flare gas measurement (DPR, 2020) (Steps 1 \& 2), improved gas utilisation via the increased gas utilisation for export and domestic use (Step 3) (NGFCP, 2019) and the revised regulatory gas flaring penalties (DPR, 2020) (Step 4). Flare gas reduction and monetisation can result in achieving several World Bank Sustainable Development Goals (SDGs) such as Agriculture (SDG 2), Good Health (SDG 3), Sustainable Cities and Communities (SDG 11), Energy Access (SDG 7) and Climate Action (SDG 13) if properly handled.

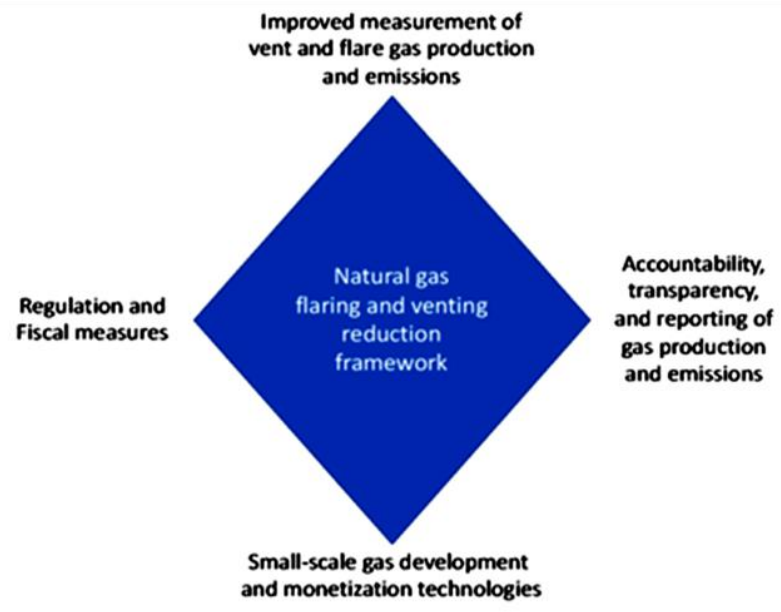

Figure 10: Integrated' Diamond model' framework to end routine flaring and venting . Source: (Romsom \& McPhail, 2021). 


\section{CONCLUSION}

Flaring Intensity measurement provides comparable data, which enables performance monitoring at various levels, including oil fields, companies, upstream contracts, and country levels. Nigeria's flaring intensity and flare volumes are on the decline as the gas utilisation rate increases with the decline in oil production, but considerable work still needs to be done to meet the Zero Routine Flaring Reduction target by 2030. The granularity of this approach will assist in identifying specific flare sites for gas flaring reduction and commercialisation. Gas flare has been identified as a potential source of natural gas feedstock in Nigeria (NGFCP, 2019); hence analysis of the historical trends and forecast of flaring intensity can play an important part in understanding the viability and bankability of the gas flare reduction and commercialisation project especially at the oilfield level. Therefore, regulatory bodies and companies are encouraged to incorporate this procedure in conjunction with already existing monitoring and reporting flaring performance methods to reduce these emissions and their related effects on the environment.

\section{REFERENCES}

Banerjee, K.; N. P. Cheremisinoff and P. N. Cheremisinoff. (1985). Flare Gas Systems Pocket Handbook. Gulf Publishing Company, Texas, USA.

Capterio. (2020). New Flaring Data accelerates Global call to action. Available online at: https://capterio.com/wpcontent/uploads/2020/07/20200722-New-Flaring-Data-

Accelerates-Call-To-Action.pdf. Accessed on January 8, 2021.

Chevron. (2020). Minimising gas flaring in the Permian. Available online at:

https://www.chevron.com/stories/minimizing-gas-flaring-inthe-permian. Accessed on January 5, 2020.

Diaa, R. A. (2021). Flare Gas Measurement - What are the options to considering cost competitiveness? Paper presented at Nigeria Hydrocarbon Measurement Conference (NiHMC2021). Abuja, Nigeria.

DPR. (2018). 2018 Nigerian Oil and Gas Industry Annual Report. Department of Petroleum Resources, Lagos, Nigeria.

DPR. (2020). Guidelines for flare gas measurement, data management \& reporting obligations. Available online at: https://www.dpr.gov.ng/wpcontent/uploads/2020/08/Guidelines-for-Flare-GasMeasurement-Data-Management-and-ReportingObligations.pdf. Accessed on September 23, 2020.

DPR. (2020). Guidelines for Flare Payments. Department of Petroleum Resources Lagos, Nigeria.

DPR. (2020). Nigeria's Proven Gas Reserve Now 203.16Tcf, says DPR. Available online at: https://www.dpr.gov.ng/nigerias-proven-gas-reserve-now203-16tcf-says-dpr/. Accessed on March 12, 2021.

Dung, E. J.; L. S. Bombom and T. O. Agusomu. (2008). The effects of gas flaring on crops in the Niger Delta, Nigeria. GeoJournal, 73: 297-305.
El-Banbi, A.; A. Alzahabi and A. El-Maraghi. (2018). PVT Property Correlations: Selection and Estimation. Gulf Professional Publishing.

Elvidge, C. D.; M. A. Zhizhin, K. E. Baugh, F. C. Hsu and T. Ghosh. (2015). Methods for Global Survey of Natural Gas Flaring from Visible Infrared Imaging Radiometer Suite Data. Energies, 1-15.

Emam, E. A. (2015). Gas Flaring in Industry: An Overview. Petroleum \& Coal, 57(5): 532-555.

ExxonMobil. (2020). Reducing natural gas flaring.

Available online at:

https://energyfactor.exxonmobil.com/insights/partners/reduci ng-natural-gas-flaring/. Accessed on January 5, 2020.

Google, (2019). Google Earth.

Available online at: https://earth.google.com/web/@5.38750713,6.65788613,16. 26434292a,917.9100697d,35y,1.25258692h,56.81661123t,Or. Accessed on March 23, 2021.

Guo, B. (2019). Well Productivity Handbook: Vertical, Fractured, Horizontal, Multi-fractured, and Radial-Fractured Wells. Gulf Professional Publishing.

Haugland, T. S.; S. Saunier, A. Pederstad, T. Holm, H. Darani, and A. Kertesheva. (2013). Associated Petroleum Gas Flaring Study for Russia, Kazakhstan, Turkmenistan and Azerbaijan. Available online at: https://www.ebrd.com/downloads/sector/sei/ap-gas-flaringstudy-final-report.pdf. Accessed on May 12, 2021.

Hodgson, R. (2018). Generating a scalable calibration equation that can be applied to VIIRS Nightfire (VNF) radiant heat calculation to estimate gas flaring volumes in Nigeria, Birkbeck, UK.

Mylvaganam, K. (1989). High-Rangeability Ultrasonic Gas Flowmeter for Monitoring Flare Gas. IEEE Transaction on Ultrasonics, Ferroelectrics and Frequency Control, 36(2): 144-149.

NAPIMS, (2021). Gas Operations. Available online at: https://napims.nnpcgroup.com/our-services/Pages/GasOperations.aspx. Accessed on October 3, 2021.

Ndunagu, U. P. (2021). Flaring Intensity approach to Gas Flare Monitoring and Utilisation in the Niger Delta. Unpublished P.hD dissertation, University of Port Harcourt, Nigeria.

NGFCP. (2019). Nigerian Gas Flare Commercialization Programme. Available online at: https://ngfcp.dpr.gov.ng/. Accessed on March 12, 2020.

NOSDRA. (2014). Nigerian Gas Flare Tracker. Available online at: https://nosdra.gasflaretracker.ng/data.html. Accessed on November 10, 2019.

Odjugo, T.; Y. Baba, A. Aliyu, N. Okereke, L. Oloyede and O. Onifade. (2020). Optimisation of Artificial Lifts using Prosper Nodal Analysis for BARBRA-1 well in Niger Delta. Nigerian Journal of Technological Development, 17(3): 150-155.

OGA, (2020). UKCS Flaring \& Venting Report, Oil \& Gas Authority, London, UK.

Ogolo, N. A.; P. Ugwu, I. Ukut, M. Otokpa, and M. Onyekonwu. (2018). Rainwater quality evaluation in a typical gas flaring environment in the Niger Delta. SPE 
Nigeria Annual International Conference and Exhibition (NAICE2018), Lagos, Nigeria, 1 - 7.

Olin, M. J. (2014). Flare Gas Mass Flow Metering. Sierra Instruments Inc, Monterey, California, USA.

Osuoha, C. A. and Fakutiju, M. A. (2017). Gas flaring in Niger Delta Region of Nigeria: Cost, Ecological and Human health implications. Environmental Management and Sustainable development, 6(2): 390 - 410.

Pitman, R. and Chinweze, A. (2018). The case for publishing petroleum contracts in Nigeria.

Available online at: https://resourcegovernance.org/sites/default/files/documents/ the-case-for-publishing-petroleum-contracts-in-nigeria.pdf. Accessed on December 11, 2020.

Romsom, E. and McPhail, K. (2021). Capturing economic and social value from hydrocarbon gas flaring and venting: solutions and actions. WIDER Working Paper 2021/6. UNU-WIDER. Helsinki, Finland.

Shell, (2015). Sustainability Report 2015. Available online at: https://reports.shell.com/sustainabilityreport/2015/managing-operations/flaring.html. Accessed on January 5, 2020.
Sitton, R. (2020). Texas Flaring Report Q1 2020. Available online at:

https://rrc.texas.gov/media/56420/sitton-texas-flaring-reportq1-2020.pdf. Accessed on January 4, 2021.

SkyTruth, (2020). Annual Flaring Volume Estimates from Earth Observation Group (2012-2018). Available online at: http://viirs.skytruth.org/apps/heatmap/flarevolume.html\#. Accessed on April 15, 2020.

Ubani, E. and Onyejekwe, I. (2013). Environmental impact analyses of gas flaring in the Niger Delta region of Nigeria. American Journal of Scientific and Industrial Research, 4(2): 246-252.

United Nations. (2012). Reducing carbon and flaring intensity: expanding access to modern energy services. Available online at: https://sustainabledevelopment.un.org/partnership/?p=845.

Accessed on January 5, 2020.

World Bank. (2019). Global Gas Flaring Data. Available online at: https://www.ggfrdata.org/. Accessed on January 4, 2021. 